\title{
Composite slim floor beams with innovative shear connections
}

1 Shiming Chen $\mathrm{PhD}$

Professor, College of Civil Engineering, Tongji University, Shanghai, China (corresponding author: chensm@tongji.edu.cn)
2 Toi Limazie MSc, PhD

Structural Engineer, JZFZ Architectural Design Co. Ltd, Chengdu, China
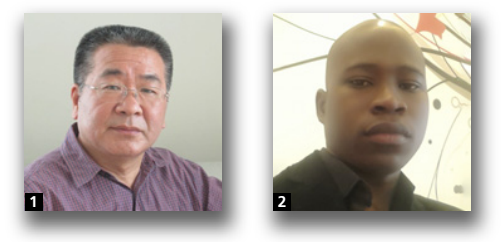

An innovative form of slim floor beams is proposed in which the shear connection is formed by combining the concrete passing through the web openings with a steel tie-bar element. A numerical study was conducted to evaluate the flexural behaviour of these composite shallow cellular beams. The force transferring mechanism, load-bearing capacity and failure patterns of the shear connections were also evaluated. Two different configurations of shear connection were designed and a parametric study was carried out to determine the parameters likely to influence their performance. The findings were incorporated with bending and push-out test results to develop design methods for this form of shear connection. A tentative design procedure for the composite shallow cellular beams is proposed.

\section{Notation}

$A_{\mathrm{c}}$

$A_{\mathrm{s}}$

$A_{\text {st }}$

$B_{\mathrm{b}}$

$B_{\text {eff }}$

$B_{\mathrm{t}}$

$D$

$D_{\text {c }}$

$D_{\mathrm{s}}$

$D_{\mathrm{tb}}$

$d$

$E_{\mathrm{c}}$

$E_{\mathrm{s}}$

$f_{\text {ct }}$

$f_{\text {cu }}$

$f_{\text {sd }}$

$f_{\mathrm{y}}$

$H_{\mathrm{s}}$

$H_{\mathrm{t}}$

$h_{\mathrm{D}}$

I

$I_{\text {comp }}$

$I_{\mathrm{s}}$

$L$

$M$

$N_{\text {i }}$

$P_{\mathrm{o}}$

$R_{\mathrm{q}}$
$R_{\mathrm{sh}}$

cross-sectional area of infill concrete (area of concrete in tensile splitting) cross-sectional area of structural steel beam cross-sectional area of reinforcing tie-bar width of bottom flange effective width of concrete slab width of top flange diameter of opening concrete topping depth above top flange of steel beam depth of concrete slab above profiled steel decking diameter of tie-bar depth of concrete slab in compression elastic modulus of concrete elastic modulus of steel element concrete tensile strength concrete cube compressive strength design yield strength of reinforcing tie-bar yield strength of steel web post depth of steel section overall depth of composite beam height of web opening second moment of inertia of composite section moment of inertia of the composite section moment of inertia of structural steel beam section span length moment resistance of composite beam number of shear connectors within a shear span opening parameter actual longitudinal shear resistance provided by shear connectors ultimate shear resistance of an individual shear connection

$R_{\mathrm{sw}} \quad$ shear resistance of steel web post

$S \quad$ web opening spacing

$S_{\mathrm{b}} \quad$ depth of steel web base

$S_{\mathrm{y}} \quad$ static moment of beam section

$t_{\mathrm{b}} \quad$ thickness of bottom flange

$t_{\mathrm{t}} \quad$ thickness of top flange

$t_{\mathrm{w}} \quad$ thickness of steel web post

$V \quad$ longitudinal shear force

$w \quad$ length of steel web post

$Y \quad$ distance between neutral axis of the composite section and the steel web post base

$y_{\text {ec }} \quad$ depth of elastic neutral axis of composite section

$y_{\mathrm{s}} \quad$ depth of elastic neutral axis of steel beam section

$\alpha_{\mathrm{e}} \quad$ modular ratio of the composite section $\left(=E_{\mathrm{s}} / E_{\mathrm{c}}\right)$

$\gamma_{\mathrm{s}} \quad$ partial safety factor for steel section $(=1 \cdot 25)$

$\sigma_{\mathrm{c}, \mathrm{Rd}} \quad$ uniaxial compressive strength of concrete

$\sigma_{\mathrm{d}} \quad$ maximum design stress within steel beam

\section{Introduction}

In recent years, there has been increasing demand for buildings that are quick to construct, have large uninterrupted floor areas and are flexible in their intended final use. Modern design and construction techniques enable steel-concrete composite construction to satisfy such demands by producing structures that are competitive in terms of resistance and overall cost. The trend is towards the use of longer spans and lightweight floor systems, which has resulted in the development of various slim floor systems (e.g. Slimflor, Slimdek, asymmetric Slimflor 
beams and ultra-shallow floor beams), likely being used in commercial and residential buildings, hospitals, schools and so on.

The composite shallow cellular floor beam (SCFB) is a generic term used to describe a type of composite slim floor construction in which the key feature is that steel beams with regularly spaced openings are contained within the concrete slab depth. This results in a flat appearance and offers important benefits in terms of cost, long spanning capabilities without (or with fewer) secondary beams, shallow floor depths, passages for building services, efficient fire resistance and so on (Hicks, 2003; Lawson et al., 1997, 1999, 2006), as well as other advantages offered by conventional composite beam construction.

They can comprise precast units, hollow-core concrete slabs with or without a concrete topping or deeply profiled steel decking and cast-in-place concrete. The embedded steel beam can be fabricated by welding two highly asymmetric T-sections together along the web and forming regularly spaced openings, or it can be obtained by welding three different steel plates with regularly spaced openings formed on the web post.

The use of composite slim floor systems requires comprehension of the behaviour of all the structural components, among which the shear forces transferring between the steel beam and the concrete slab are the most important aspect. In ordinary slim floor beams such as Slimflor, Slimdek and asymmetric Slimflor beams, shear transfer is only assumed by the bonding effect at the interface between the concrete and the steel beam. However, this adhesive strength has been found to be very limited and is prone to shear failure under small loads. An enhanced form of slim floor beam, called the composite shallow cellular slim floor beam, designed with an effective and innovative shear connection configuration is proposed. It consists of a row of regularly spaced openings preformed within the web post, which provide passage for the concrete cast-in-place. The infill concrete combines with the additional steel reinforcing bar to form a shear connection that is able to

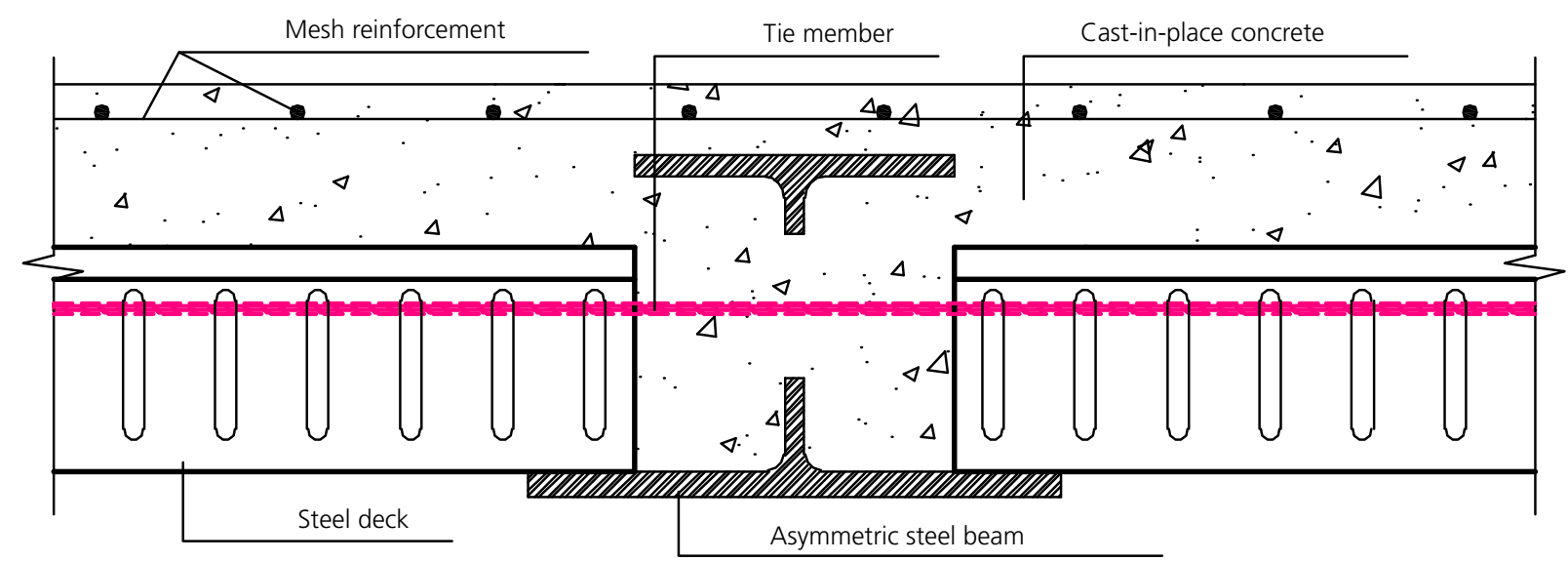

(a)

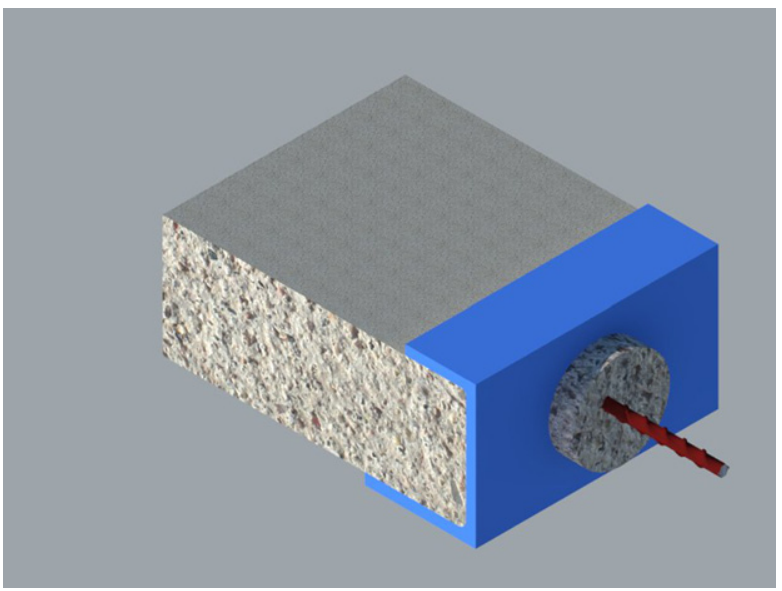

(b)

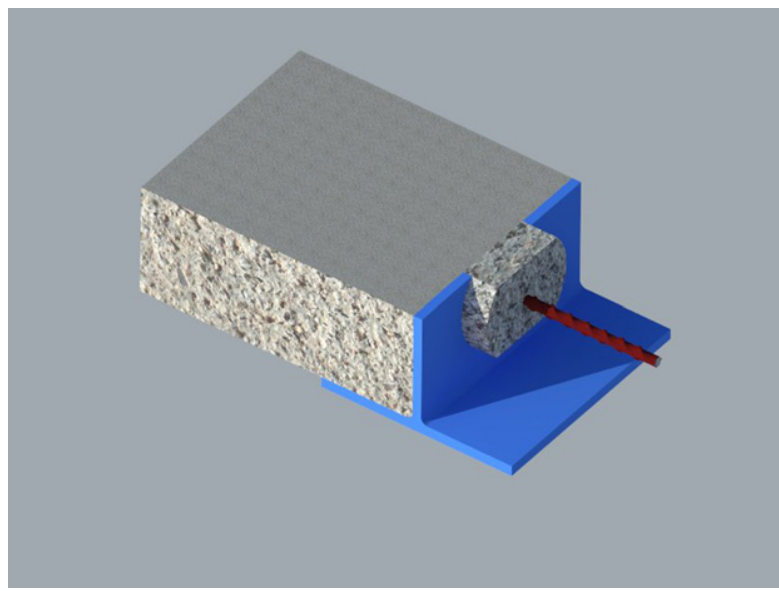

(c)

Figure 1. Proposed shear connection system: (a) typical arrangement of shear connection with circular opening configuration; (b) circular opening shear connection; (c) clothoidal opening shear connection 
transfer longitudinal shear forces between the concrete slab and the encased steel beam (Figure 1(a)).

Slim floor systems have been studied previously (Lawson et al., 1997, 1999; Mullett, 1998) and experimental studies on integrated slim beams were conducted at Helsinki University of Technology (Bernuzzi et al., 1995). Mullett (1992) proposed design guidance for Slimflor beams using hollow-core precast units, while Mullett and Lawson (1993) investigated the behaviour of slim floors as well as the shear transfer mechanism between the steel beam and the concrete slab. Wang et al. (2009) reported on an experimental investigation of the flexural behaviour of slim floor beams using deep decking. However, the mechanism of this integrated composite beam is not yet well understood and the roles that shear connections and shear transfer play in the overall behaviour of a composite slim floor have been overlooked.

Research into shear connection systems and composite action within slim floor systems is very rarely reported in the literature. Huo and D'Mello (2013) presented 24 full-scale push-out tests to investigate shear connections for shallow cellular beams, under direct longitudinal shear force.

The research reported in this paper combined the results of an experimental programme finite-element analysis (FEA) conducted on four full-scale SCFBs. The scope of the study was to investigate the load-bearing behaviour and the longitudinal shear transferring mechanism, and to provide benchmarks for the evaluation of the flexural performance and longitudinal shear resisting capacity in slim floor beam systems. A further aim was to develop a design method and pre-design tools for shallow cellular slim floor beams.

\section{Description of the innovative shear connection}

The enhanced form of the SCFB developed is capable of producing efficient shallow floor constructions with greater spanning capability and more significant load-bearing capacity. For this particular form of composite beam, a steel beam with regular openings along the steel web is embedded within the concrete floor. In addition, reinforcing steel bars pass through the middle of the web openings and are anchored within the ribs of the steel decking. The cast-in-place concrete passing through the web openings is able to combine with the reinforcing bars to produce an effective shear connection system, this being referred to as a 'concrete plug with tie-bar shear connection'.

Two different configurations of shear connections were devised and designed, representing different web opening geometries: circular opening and clothoidal opening shear connections. The circular opening configuration is cut from an asymmetric I-section steel beam, while the clothoidal opening is cut from an inverted T-section steel beam (Figures 1(b) and 1(c)).

\section{Composite shallow cellular floor beam tests}

Flexural load tests were carried out on both partially and fully encased composite SCFBs. The key parameters investigated were the configuration of the steel beam, the configuration of the web openings and the configuration of the concrete slab. Details of the flexural tests and the numerical analysis results have been presented elsewhere (Chen et al., 2015; Limazie and Chen, 2016). The effectiveness of the SCFB with the proposed shear connection system was demonstrated. All specimens experienced significant ductile behaviour, effective loadbearing capacity and significant composite behaviour. The experimental and numerical investigations also revealed the shear transfer and failure mechanisms of the shear connections (Chen et al., 2015; Limazie, 2015; Limazie and Chen, 2016).

\section{Analytical procedures for design of the SCFB and the shear connection system}

The experiments and numerical parametric studies previously conducted provided important and comprehensive information on the load-bearing behaviour, the shear resisting capacity and the overall behaviour of the shear connection system.

The results of these investigations showed that the longitudinal shear resisting capacity of the shear connection system is contributed to by a combination of the resistance of both the infill concrete element and the tie-bar element. The force transferring mechanism of the concrete plug with tie-bar shear connection was deduced and is illustrated in Figure 2. The ultimate shear resistance of the shear connection can be calculated from the summation of the concrete compressive capacity and the tensile strength provided by both the infill concrete and the ratio of embedded reinforcement (tie-bar). This is mathematically expressed as

1. $R_{\mathrm{sh}}=1 \cdot 2\left(t_{\mathrm{w}} h_{\mathrm{D}} f_{\mathrm{cu}}\right)+2 \cdot 1 A_{\mathrm{c}} f_{\mathrm{ct}}\left(1+13 \cdot 5 \frac{E_{\mathrm{s}} A_{\mathrm{st}}}{E_{\mathrm{c}} A_{\mathrm{c}}}\right)$

in which $A_{\mathrm{st}}=\pi D_{\mathrm{tb}}^{2} / 4$.

The first part of Equation 1 represents the local compressive capacity of the shear connection and the second part represents the tensile splitting strength of the shear connection, combining the infill concrete and the tie-bar. A typical concrete plug with tie-bar element is illustrated in Figure 3(a).

To participate in the overall composite action, the shear connection should be designed with an optimum reinforcing ratio, expressed as

2. $A_{\mathrm{st}} \geq \frac{0 \cdot 2 R_{\mathrm{sh}}}{f_{\mathrm{sd}}}$ 

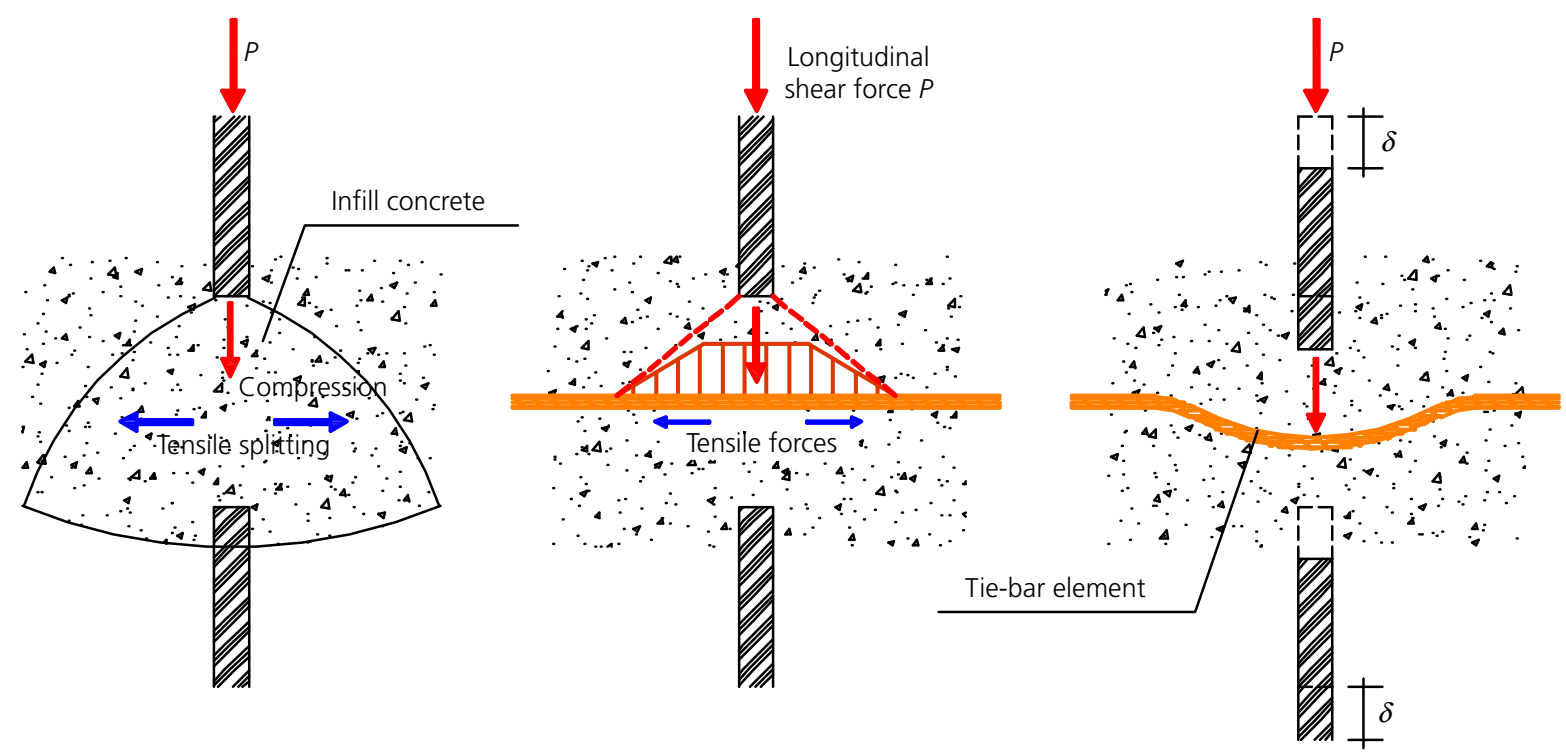

Figure 2. Illustration of a typical force transfer mechanism in shear connection

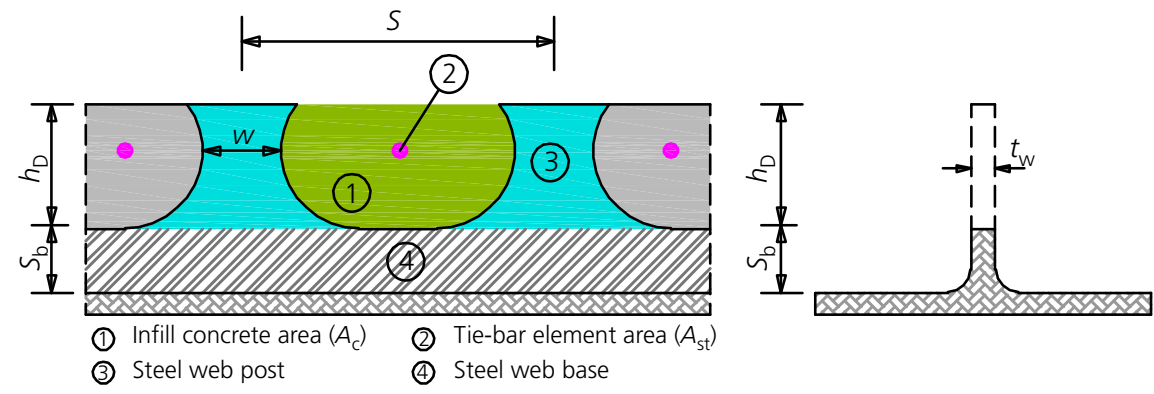

(a)

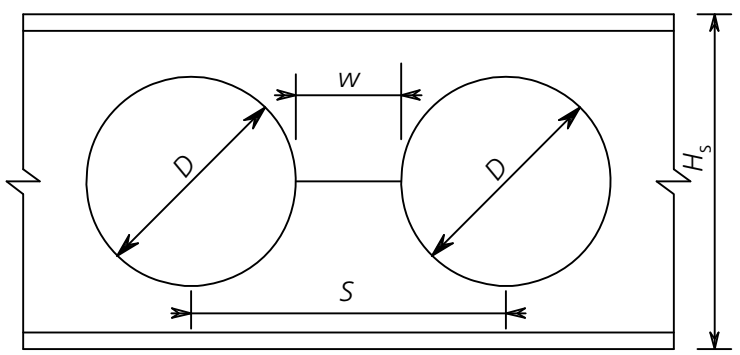

(b)

Figure 3. Terminology of (a) typical concrete plug with tie-bar element and (b) geometry of steel section

The amount of shear connectors required to ensure full shear interaction within a shear span can be obtained from

3. $N_{\mathrm{i}}=R_{\mathrm{q}} / R_{\mathrm{sh}}$

where $R_{\mathrm{q}}$, the actual longitudinal shear resistance provided by shear connectors, is determined as

4. $R_{\mathrm{q}}=\left(\sigma_{\mathrm{c}, \mathrm{Rd}} B_{\mathrm{eff}}\right) d$ wherein $\sigma_{\mathrm{c}, \mathrm{Rd}}$ is the uniaxial compressive strength of concrete, $B_{\text {eff }}$ is the effective width of the concrete slab and $d$ is the depth of concrete slab in compression.

The available degree of shear connection along the composite beam can therefore be derived as

5. $\eta=R_{\mathrm{q}} / R_{\mathrm{c}}$ 
in which $R_{\mathrm{c}}$ is the compressive resistance of concrete slab in full shear connection determined by the stress block method (Limazie and Chen, 2015).

Test results on 14 push-out specimens with circular openings (Huo and D'Mello, 2013) and 31 numerical simulation results concerning various opening configurations (Limazie, 2015; Limazie and Chen, 2017) were used to calibrate and verify the method proposed in Equation 1. The comparisons are given in Tables 1 and 2. The average ratios of the calculated shear resistance to the experimental results and the FEA results were 0.99 and 0.76 respectively, indicating that the proposed

Table 1. Comparison of experimental shear resistance $\left(R_{\text {sh,exp }}\right)$ from push-out tests (Huo and D'Mello, 2013) and analytical results $\left(R_{\text {sh,calc }}\right)$ obtained using Equation 1

\begin{tabular}{|c|c|c|c|c|c|c|c|c|c|}
\hline Specimen & $f_{\mathrm{cu}}: \mathrm{MPa}$ & $f_{\mathrm{ct}}: \mathrm{MPa}$ & $A_{\mathrm{c}}: \mathrm{mm}^{2}$ & $h_{\mathrm{D}}: \mathrm{mm}$ & $t_{w}: m m$ & $D_{\mathrm{tb}}: \mathrm{mm}$ & $R_{\text {sh,calc: }} \mathbf{k N}$ & $\boldsymbol{R}_{\text {sh,exp: kN }}$ & $\boldsymbol{R}_{\mathrm{sh}, \mathrm{calc}} / \boldsymbol{R}_{\mathrm{sh}, \exp }$ \\
\hline T1-B-N & $55 \cdot 6$ & $4 \cdot 53$ & 31416 & 200 & $9 \cdot 9$ & - & 429 & 362 & $1 \cdot 18$ \\
\hline T1-B-F & $58 \cdot 1$ & $4 \cdot 85$ & 31416 & 200 & $9 \cdot 9$ & - & 455 & 397 & $1 \cdot 14$ \\
\hline T5-1 & 35 & $3 \cdot 21$ & 17671 & 150 & $8 \cdot 6$ & - & 173 & 226 & 0.76 \\
\hline T5-2 & 35 & $3 \cdot 21$ & 17671 & 150 & $8 \cdot 6$ & - & 173 & 194 & 0.89 \\
\hline T5-3 & 32 & $2 \cdot 9$ & 17671 & 150 & $8 \cdot 6$ & - & 157 & 182 & 0.86 \\
\hline T5-4 & 30 & 3.02 & 17671 & 150 & $8 \cdot 6$ & - & 158 & 175 & 0.90 \\
\hline T2-A-N & 54.5 & $4 \cdot 54$ & 17671 & 150 & $8 \cdot 6$ & $2 \varnothing 12$ & 426 & 309 & $1 \cdot 37$ \\
\hline T2-A-F & $51 \cdot 9$ & 4.07 & 17671 & 150 & 8.6 & $2 \varnothing 12$ & 384 & 305 & 1.25 \\
\hline T2-B-N & 54.5 & 4.54 & 31416 & 200 & $9 \cdot 9$ & $2 \varnothing 12$ & 584 & 390 & 1.45 \\
\hline T2-B-F & $51 \cdot 9$ & 4.07 & 31416 & 200 & $9 \cdot 9$ & $2 \varnothing 12$ & 526 & 372 & $1 \cdot 41$ \\
\hline T6-1 & 29 & $2 \cdot 85$ & 17671 & 150 & $8 \cdot 6$ & $1 \varnothing 16$ & 259 & 391 & 0.66 \\
\hline T6-2 & 32 & $2 \cdot 92$ & 17671 & 150 & $8 \cdot 6$ & $1 \varnothing 16$ & 269 & 386 & 0.70 \\
\hline T6-3 & 28 & $2 \cdot 49$ & 17671 & 150 & 8.6 & $1 \widetilde{\varnothing 16}$ & 230 & 327 & 0.70 \\
\hline T6-4 & 27 & $2 \cdot 57$ & 17671 & 150 & $8 \cdot 6$ & $1 \widetilde{\varnothing 16}$ & 235 & 358 & 0.66 \\
\hline Average & & & & & & & & & 0.99 \\
\hline
\end{tabular}

Table 2. Comparison of shear resistance from FEA $\left(R_{\text {sh,FEA }}\right)$ (Limazie, 2015; Limazie and Chen, 2017) and analytical results $\left(R_{\text {sh,calc }}\right)$ obtained using Equation 1

\begin{tabular}{|c|c|c|c|c|c|c|c|c|c|}
\hline Specimen & $f_{\mathrm{cu}}: \mathrm{N} / \mathrm{mm}^{2}$ & $f_{\mathrm{ct}}: \mathrm{N} / \mathrm{mm}^{2}$ & $A_{\mathrm{c}}: \mathrm{mm}^{2}$ & $h_{\mathrm{D}}: \mathrm{mm}$ & $t_{\mathrm{w}}: \mathrm{mm}$ & $D_{\mathrm{tb}}: \mathrm{mm}$ & $R_{\text {sh,calc: }}: \mathbf{N}$ & $R_{\text {sh,FEA }}: \mathbf{k N}$ & $\boldsymbol{R}_{\text {sh,calc }} / \boldsymbol{R}_{\text {sh,FEA }}$ \\
\hline $\mathrm{CO}-1$ & 30 & $2 \cdot 10$ & 14000 & 134 & 14 & - & 130 & 189 & 0.69 \\
\hline $\mathrm{CO}-2$ & 30 & $2 \cdot 10$ & 8400 & $103 \cdot 5$ & 14 & - & 105 & 125 & 0.84 \\
\hline $\mathrm{CO}-3$ & 30 & $2 \cdot 10$ & 4200 & $73 \cdot 2$ & 14 & - & 56 & 84 & 0.67 \\
\hline$C L-C-1$ & 30 & $2 \cdot 10$ & 14000 & 124 & 14 & - & 124 & 180 & 0.69 \\
\hline CL-C-2 & 30 & $2 \cdot 10$ & 8400 & $96 \cdot 5$ & 14 & - & 99 & 127 & 0.78 \\
\hline CL-C-3 & 30 & $2 \cdot 10$ & 4200 & $68 \cdot 5$ & 14 & - & 81 & 95 & 0.85 \\
\hline$C L-C E$ & 30 & $2 \cdot 10$ & 14000 & 100 & 14 & - & 112 & 154 & 0.73 \\
\hline$C L-Z$ & 30 & $2 \cdot 10$ & 14000 & 100 & 14 & - & 117 & 165 & $0 \cdot 71$ \\
\hline $\mathrm{CO}-\mathrm{FC} 25$ & 25 & $1 \cdot 80$ & 14000 & 134 & 14 & - & 109 & 141 & 0.77 \\
\hline CO-FC30 & 30 & $2 \cdot 10$ & 14000 & 134 & 14 & - & 130 & 189 & 0.69 \\
\hline CO-FC40 & 40 & $2 \cdot 80$ & 14000 & 134 & 14 & - & 173 & 209 & $0 \cdot 83$ \\
\hline CO-FC50 & 50 & $3 \cdot 50$ & 14000 & 134 & 14 & - & 215 & 302 & 0.72 \\
\hline CL-C-FC25 & 25 & $1 \cdot 80$ & 14000 & 124 & 14 & - & 105 & 157 & 0.67 \\
\hline CL-C-FC30 & 30 & $2 \cdot 10$ & 14000 & 124 & 14 & - & 125 & 180 & 0.69 \\
\hline CL-C-FC40 & 40 & $2 \cdot 80$ & 14000 & 124 & 14 & - & 157 & 239 & 0.66 \\
\hline CL-C-FC50 & 50 & $3 \cdot 50$ & 14000 & 124 & 14 & - & 207 & 296 & $0 \cdot 70$ \\
\hline CO-Tw10 & 30 & $2 \cdot 10$ & 14000 & 134 & 10 & - & 110 & 151 & 0.73 \\
\hline CO-Tw14 & 30 & $2 \cdot 10$ & 14000 & 134 & 14 & - & 130 & 189 & 0.69 \\
\hline CO-Tw20 & 30 & $2 \cdot 10$ & 14000 & 134 & 20 & - & 159 & 265 & 0.60 \\
\hline CL-C-Tw10 & 30 & $2 \cdot 10$ & 14000 & 124 & 10 & - & 106 & 127 & $0 \cdot 84$ \\
\hline CL-C-Tw14 & 30 & $2 \cdot 10$ & 14000 & 124 & 14 & - & 124 & 180 & 0.69 \\
\hline CL-C-Tw20 & 30 & $2 \cdot 10$ & 14000 & 124 & 20 & - & 151 & 221 & 0.69 \\
\hline $\mathrm{CO}-\mathrm{O}-3+\varnothing 8$ & 30 & $2 \cdot 10$ & 4200 & $73 \cdot 2$ & 14 & $1 \varnothing 8$ & 77 & 101 & 0.75 \\
\hline $\mathrm{CO}-\mathrm{O}-3+\varnothing 10$ & 30 & $2 \cdot 10$ & 4200 & $73 \cdot 2$ & 14 & $1 \varnothing 10$ & 88 & 113 & $0 \cdot 78$ \\
\hline $\mathrm{CO}-\mathrm{O}-3+\varnothing 12$ & 30 & $2 \cdot 10$ & 4200 & $73 \cdot 2$ & 14 & $1 \varnothing 12$ & 103 & 133 & 0.77 \\
\hline $\mathrm{CO}-\mathrm{O}-3+\varnothing 14$ & 30 & $2 \cdot 10$ & 4200 & $73 \cdot 2$ & 14 & $1 \varnothing 14$ & 120 & 144 & 0.83 \\
\hline $\mathrm{CO}-\mathrm{O}-3+\varnothing 16$ & 30 & $2 \cdot 10$ & 4200 & $73 \cdot 2$ & 14 & $1 \varnothing 16$ & 139 & 153 & 0.91 \\
\hline $\mathrm{CO}-\mathrm{O}-3+\varnothing 20$ & 30 & $2 \cdot 10$ & 4200 & $73 \cdot 2$ & 14 & $1 \varnothing 20$ & 186 & 162 & $1 \cdot 14$ \\
\hline$C L-C-1+\varnothing 8$ & 30 & $2 \cdot 10$ & 14000 & 124 & 14 & $1 \varnothing 8$ & 145 & 199 & 0.73 \\
\hline$C L-C-1+\varnothing 12$ & 30 & $2 \cdot 10$ & 14000 & 124 & 14 & $1 \varnothing 12$ & 171 & 252 & 0.68 \\
\hline$C L-C-1+\varnothing 16$ & 30 & $2 \cdot 10$ & 14000 & 124 & 14 & $1 \varnothing 16$ & 208 & 297 & $0 \cdot 70$ \\
\hline Average & & & & & & & & & 0.76 \\
\hline
\end{tabular}


analytical method is reliable and accurate in predicting the longitudinal shear resistance of a concrete plug with tie-bar shear connection.

For the local composite action, the steel web post serves to introduce longitudinal shear forces into the infill concrete, leading to significant stresses within the steel part of the shear connection. The longitudinal shear resistance of the steel web post can be obtained from

6. $R_{\mathrm{sw}}=0 \cdot 25 S t_{\mathrm{w}} f_{\mathrm{y}}$

Based on detailed FEA and analytical calculations (Limazie, 2015; Limazie and Chen, 2017), the stress concentration and the maximum design stress within the steel beam part were derived, and can be divided into the stresses caused by the composite action within the opening from the longitudinal shear forces and the stresses caused by the bending moment and axial force, as illustrated in Figure 4. Therefore, the maximum design stress within the steel section part can be estimated using

7. $\sigma_{\mathrm{d}}=8 \cdot 5\left(\frac{V S_{\mathrm{y}}}{t_{\mathrm{w}} I}\right)+1.5\left(\frac{M}{I} Y\right) \leq \frac{f_{\mathrm{y}}}{\gamma_{\mathrm{s}}}$

On the basis of this work, the following geometrical requirements are proposed for the purposes of economy and overall stability of the composite beam.

- The relationship between the depth of the opening $\left(h_{\mathrm{D}}\right)$ and the spacing between adjacent opening $(S)$ should satisfy

\section{8. $h_{\mathrm{D}}=0 \cdot 6 \mathrm{~S}$}

The steel web post length $(w)$ between two adjacent openings should satisfy

9. $w \geq 0 \cdot 5 h_{\mathrm{D}}$

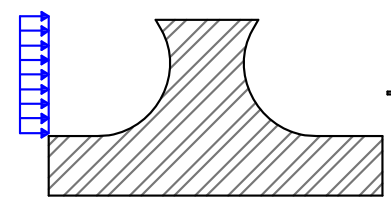

Local composite action

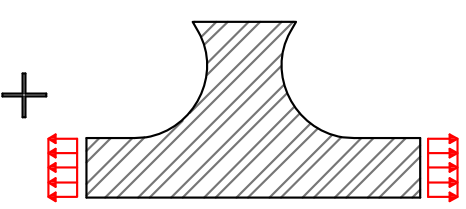

Bending and axial force actions
Figure 4. Different action forces inducing stress concentration within a steel element with clothoidal opening shear connection
The depth of the steel web base $\left(S_{\mathrm{b}}\right.$, shown in Figure 3(a)) should not be less than $20 \mathrm{~mm}$ or less than two times the steel web thickness $\left(S_{\mathrm{b}} \geq 2 t_{\mathrm{w}}\right)$.

\section{Design approach for determining flexural stiffness}

The strain/stress distribution within the elastic state observed in tests (Chen et al., 2015) revealed the following.

(a) The stresses at the top fibre of the concrete slab within pure bending and along the slab width region were uniformly distributed.

(b) The stresses recorded by strain gauges attached to the concrete slab along the slab depth were linear.

(c) The stresses recorded on the structural steel beam and on the concrete slab, almost at the same position, behaved similarly and were almost identical, indicating that there were no slips between the two elements.

(d) The stresses measured along the slab depth revealed that the stress of the concrete within the steel decking was very small and almost negligible.

All of these events were also observed during the FEA, confirming the load-bearing behaviour of the SCFB and the stress distribution during the loading process.

Based on the above observations, elastic theory with the plane section assumption and the mechanics of materials were used to implement a calculation method for the flexural stiffness of SCFB. It is recognised that the flexural stiffness of the composite beam would vary along the beam length, as the crosssection also varies from one section to another. However, the difference between considering the stiffness at the mid-span cross-section and the average stiffness along the beam length is relatively small. For simplicity, the method supposes the midspan section stiffness as the stiffness of the entire composite beam section. The following assumptions were made in calculating the flexural stiffness of the composite floor beam.

(a) The concrete slab section within the profiled steel decking does not participate in the load-bearing behaviour of the composite beam and is therefore ignored.

(b) The reinforcing bars within the concrete slab and the steel decking are ignored.

(c) In the elastic state, the steel beam and the compressive concrete remain plane and perfectly linear-elastic, and behave compositely without slips at their contact interface.

Using these principles and transformations, the flexural stiffness of the composite SCFB $(G)$ can be expressed as

10. $G=E_{\mathrm{s}} I_{\mathrm{comp}}$ 
where $E_{\mathrm{s}}$ is the elastic modulus of the steel beam and $I_{\text {comp }}$ is the moment of inertia of the composite section, which can be obtained from

$$
\text { 11. } I_{\text {comp }}=I_{\mathrm{s}}+A_{\mathrm{s}}\left(y_{\mathrm{s}}-y_{\mathrm{ec}}\right)^{2}+\frac{A_{\mathrm{c}}}{\alpha_{\mathrm{e}}} \frac{D_{\mathrm{s}}^{2}}{12}+\frac{A_{\mathrm{c}}}{\alpha_{\mathrm{e}}}\left(\frac{D_{\mathrm{s}}}{2}-D_{\mathrm{c}}-y_{\mathrm{ec}}\right)^{2}
$$

in which $A_{\mathrm{c}}$ is the cross-sectional area of concrete slab.

The position of the neutral axis of the composite SCFB section can be calculated from

$$
\text { 12. } y_{\mathrm{ec}}=\left[A_{\mathrm{s}} y_{\mathrm{s}}+\frac{A_{\mathrm{c}}}{\alpha_{\mathrm{e}}}\left(\frac{D_{\mathrm{s}}}{2}-D_{\mathrm{c}}\right)\right] /\left(A_{\mathrm{s}}+\frac{A_{\mathrm{c}}}{\alpha_{\mathrm{e}}}\right)
$$

where $\alpha_{\mathrm{e}}$ is the modular ratio of the composite section ( $=E_{\mathrm{s}} / E_{\mathrm{c}}$ ), with $E_{\mathrm{s}}$ and $E_{\mathrm{c}}$ being the elastic modulus of steel and concrete, respectively.

The cross-sectional properties of the tested specimens are summarised in Table 3. The flexural stiffness calculated using Equation 10 is compared with the test values in Table 4, for different load levels in the elastic state. The difference between the calculated and test values was relatively small and thus the proposed calculation method can accurately predict the flexural characteristics of the shallow cellular composite beam.

\section{Pre-design tools for shallow cellular composite slim floor beams}

Differences in structural configurations will mean that significant changes need to be considered in the design and construction of shallow cellular composite slim floors. The appropriateness of design guidance and checks for different stages (construction and normal-use stages) would thus be very important, but cumbersome.

Detailed design procedures for shallow cellular composite floors based on the stress block method have been established and have led to pre-design tables and figures that could be used for practical purposes. The pre-design tools mainly consist of tables and graphs giving the allowable loading capacity for a wide range of composite beam sections for spans of $3-10 \mathrm{~m}$. The load-bearing capacities of both steel beams and composite sections were determined using the plastic analysis procedure (Limazie and Chen, 2015). Eight cases of shallow cellular composite slim floor beams were studied, and two different steel beam configurations were designed (the asymmetric I-section steel beam and the inverted T-section steel beam) with different opening sizes, different steel decking depth and different span length.

\subsection{Pre-design tools for the structural steel beam}

For both I- and T-sections, the size and spacing of the openings are governed by the longitudinal shear resistance of the composite section, as detailed in previous sections. However, some specific limitations are proposed here and should be considered in the selection and checking of the steel section. To propose realistic and economic solutions, steel sections should be selected ensuring that they approximately fulfil the condition

13. $L / 25 \leq H_{\mathrm{s}} \leq L / 30$

\begin{tabular}{|c|c|c|c|c|c|c|c|c|c|c|c|c|}
\hline Specimen & $B_{\text {eff }}$ & $H_{\mathrm{t}}$ & $D_{\mathrm{c}}$ & $B_{\mathrm{b}}$ & $B_{\mathrm{t}}$ & $t_{\mathrm{b}}$ & $t_{\mathrm{t}}$ & $t_{w}$ & $H_{\mathrm{s}}$ & $\alpha_{\mathrm{e}}$ & $y_{\text {ec }}$ & $I_{\text {comp }}: \mathrm{mm}^{4} \mathrm{a}$ \\
\hline SCFB 1 & 1000 & 200 & 38 & 250 & 150 & 14 & 10 & 10 & 162 & $5 \cdot 81$ & $37 \cdot 47$ & $7.97 \times 10^{7}$ \\
\hline SCFB 2 & 1000 & 162 & - & 250 & 150 & 14 & 10 & 10 & 162 & 5.89 & $58 \cdot 46$ & $4.97 \times 10^{7}$ \\
\hline SCFB 3 & 1000 & 200 & 38 & 250 & 150 & 14 & 10 & 10 & 152 & $5 \cdot 87$ & 38.97 & $7.04 \times 10^{7}$ \\
\hline SCFB 4 & 1000 & 152 & - & 250 & 150 & 14 & 10 & 10 & 152 & $5 \cdot 67$ & $60 \cdot 59$ & $3.96 \times 10^{7}$ \\
\hline
\end{tabular}

Table 3. Geometrical characteristics and calculated moment of inertia of the beam specimens

${ }^{a}$ Calculated moment of inertia

\begin{tabular}{|c|c|c|c|c|c|}
\hline \multirow[b]{3}{*}{ Specimen } & & & \multicolumn{3}{|c|}{ Experimental value } \\
\hline & \multicolumn{2}{|c|}{ Calculated value } & \multicolumn{3}{|c|}{$G\left(=E_{s} I_{\text {comp }}\right)^{a}$} \\
\hline & $y_{\mathrm{ec}}(\mathrm{mm})$ & $G\left(=E_{s} I_{\text {comp }}\right)$ & Span/500 & Span/360 & Span/200 \\
\hline SCFB 1 & 37.47 & $1.5 \times 10^{13}$ & $1.37 \times 10^{13}$ & $1.42 \times 10^{13}$ & $1.28 \times 10^{13}$ \\
\hline SCFB 2 & 58.46 & $9.3 \times 10^{12}$ & $9.45 \times 10^{12}$ & $9 \cdot 37 \times 10^{12}$ & $9.14 \times 10^{12}$ \\
\hline SCFB 3 & 38.97 & $1.3 \times 10^{13}$ & $1.37 \times 10^{13}$ & $1.32 \times 10^{13}$ & $1.07 \times 10^{13}$ \\
\hline SCFB 4 & $60 \cdot 59$ & $7.4 \times 10^{12}$ & $6.90 \times 10^{12}$ & $6.61 \times 10^{12}$ & $5.99 \times 10^{12}$ \\
\hline
\end{tabular}

Table 4. Comparison of flexural stiffness between analytical and experimental results 
where $L$ is the span length and $H_{\mathrm{s}}$ is the depth of the steel section. Here, the span length was varied from $3 \mathrm{~m}$ to $10 \mathrm{~m}$ in increments of $1 \mathrm{~m}$.

\subsubsection{Geometrical conditions}

The opening diameter $(D)$ and the height of the steel beam section $\left(H_{\mathrm{s}}\right)$ are chosen as follows.

The opening parameter $\left(P_{\mathrm{o}}\right)$ should be limited to a maximum value of $6 \cdot 0$, as

$$
\text { 14. } P_{\mathrm{o}}=1+\frac{6 D}{H_{\mathrm{s}}}
$$

The clear spacing of openings should fulfil the condition

$$
\text { 15. } S \geq 1 \cdot 2 D
$$

The web post length $(w)$ should satisfy the condition

16. $w \geq 2 t_{\mathrm{w}}$

where $t_{\mathrm{w}}$ is the web post thickness.

In the pre-design example (tables and graphs, Limazie (2015)), the overall depth of the selected steel beams was varied from a minimum of $150 \mathrm{~mm}$ to a maximum of $280 \mathrm{~mm}$. The opening diameter was varied from a minimum of $80 \mathrm{~mm}$ to a maximum of $180 \mathrm{~mm}$.

\subsubsection{Profiles and steel grades}

The steel beam sections were assumed to be obtained by welding different steel plates to form the desired sections (built-up section). For convenience, the steel beams were labelled as ICB (ICB150-ICB280) and TCB (TCB150-TCB280) for asymmetric I-sections and inverted T-sections respectively. ICB150 and TCB150 refer to a composite section with a $150 \mathrm{~mm}$ height asymmetric I-section and inverted T-section respectively. Only steel grade Q345 was adopted in this pre-design, with a nominal design strength of $345 \mathrm{~N} / \mathrm{mm}^{2}$ for an element of thickness $t_{\mathrm{w}} \leq 16 \mathrm{~mm}$ or $335 \mathrm{~N} / \mathrm{mm}^{2}$ for an element of thickness $t_{\mathrm{w}}>16 \mathrm{~mm}$; the elastic modulus was considered equal to $206000 \mathrm{~N} / \mathrm{mm}^{2}$. The layout of the pre-design calculations (loading capacity and deflection capacity) follows the format of plastic analysis principles (Limazie and Chen, 2015).

\subsection{Pre-design tools for shallow cellular composite slim floor beams}

Calculations for the composite SCFBs are similar to those performed for cellular steel beams except that the composite action significantly increases the loading capacity and deflection capacity of the composite beams. The layout of the pre-design calculations for the composite section also follows the format of the plastic analysis principle presented by Limazie and Chen (2015).

The pre-design tools for composite SCFBs with the asymmetric I-section profiles and the inverted T-section profiles are presented in tables and graphs. They provide the loading and deflection capacities of the composite beams for various span lengths. ICB3-ICB10 refer to composite beams having respectively 150-280 mm high steel I-sections, while TCB3-TCB10 refer to composite beams using T-sections of the same height. The load capacity is taken as the uniform load distributed over the beam span. Therefore, it should be noted that the load and deflection capacities are mainly influenced by the span length.

\section{Conclusions}

The composite shallow cellular floor beam (SCFB) is a new form of composite floor system that offers many advantages and can be effectively used in modern building construction. An enhanced design for SCFBs with an innovative shear connection formed by combining tie-bar elements with infill concrete passing through the steel web openings has been presented. Analytical design procedures for 'concrete plug with tie-bar' type shear connections and the overall shallow cellular composite slim floor beam have been presented and the results were validated against experimental tests and numerical analyses. Design guidance for the composite SCFBs, which offers simple and reliable tools for the pre-design of composite SCFBs, has also been proposed.

\section{Acknowledgements}

The authors greatly appreciate the National Science Foundation of the People's Republic of China for support for this research under grant no. 51578407. The funding, cooperation and assistance of many people from the organisation are greatly acknowledged. The authors also acknowledge with thanks the provision of steel work by Far East Steel Structure Engineering (China Co., Ltd), and the assistance of technicians at the National Key Laboratory of Disaster Reduction in Civil Engineering of Tongji University.

\section{REFERENCES}

Bernuzzi C, Gadotti F and Zandonini R (1995) Semi-continuity in slim floor steel-concrete composite systems. In Proceedings of the 1995 1st European Conference on Steel Structures, EUROSTEEL'95, Athens, Greece. Balkema, Rotterdam, the Netherlands, pp. 287-294

Chen SM, Limazie T and Tan JY (2015) Flexural behavior of shallow cellular composite floor beams with innovative shear connections. Journal of Constructional Steel Research 106(1): 329-346.

Hicks S (2003) Current trends in modern floor construction. Magazine of the British Constructional Steelwork Association 11(1): 32-33.

Huo BY and D'Mello CA (2013) Shear transfer mechanisms in composite shallow cellular floor beams. Journal of Constructional Steel Research 88(1): 191-205. 
Lawson RM, Mullett DL and Rackham JW (1997) Design of Asymmetric Slimflor Beams Using Deep Composite Decking. The Steel Construction Institute, Ascot, UK, Publication P175.

Lawson RM, Bode H, Brekelmans JWPM, Wright PJ and Mullett DL (1999) 'Slimflor' and 'Slimdek' construction: European developments. Journal of Structural Engineering 77(8): 22-30.

Lawson RM, Lim J, Hicks SJ and Simms WI (2006) Design of composite asymmetric cellular beams and beams with large web openings. Journal of Constructional Steel Research 62(6): 614-629.

Limazie T (2015) Shear Transferring Mechanism and Structural Behavior of Shallow Cellular Composite Slim Floor Beams with Innovative Shear Connections. PhD thesis, Tongji University, Shanghai, China.

Limazie T and Chen SM (2015) Numerical procedure for nonlinear behavior analysis of composite slim floor beams. Journal of Constructional Steel Research 106(1): 209-2019.
Limazie T and Chen SM (2016) FE modeling and numerical investigation of shallow cellular composite floor beams. Journal of Constructional Steel Research 119(1): 190-201.

Limazie T and Chen SM (2017) Effective shear connection for shallow cellular composite floor beams. Journal of Constructional Steel Research 128(1): 772-788.

Mullett DL (1992) Slim Floor Design and Construction. The Steel Construction Institute, Ascot, UK, Publication P110.

Mullett DL (1998) Composite Floor Systems. Blackwell Science Ltd, Oxford, UK.

Mullett DL and Lawson RM (1993) Slim Floor Construction Using Deep Decking. The Steel Construction Institute, Ascot, UK, Publication P127.

Wang Y, Yang L, Shi Y and Zhang R (2009) Loading capacity of composite slim frame beams. Journal of Constructional Steel Research 65(3): 650-661.

\section{How can you contribute?}

To discuss this paper, please email up to 500 words to the editor at journals@ice.org.uk. Your contribution will be forwarded to the author(s) for a reply and, if considered appropriate by the editorial board, it will be published as discussion in a future issue of the journal.

Proceedings journals rely entirely on contributions from the civil engineering profession (and allied disciplines). Information about how to submit your paper online is available at www.icevirtuallibrary.com/page/authors, where you will also find detailed author guidelines. 